\title{
INTEGRAÇÃO DO MÉTODO AHP E SIG COMO INSTRUMENTO DE ANÁLISE DO NÍVEL DE CONSERVAÇÃO AMBIENTAL EM BACIAS HIDROGRÁFICAS
}

\author{
INTEGRATION OF THE AHP METHOD AND GIS AS AN ANALYSIS INSTRUMENT OF THE \\ ENVIRONMENTAL CONSERVATION LEVEL IN HYDROGRAPHIC BASINS
}

Raylton de Carvalho GOMES; Edilson Souza BIAS
Universidade de Brasília, Instituto de Geociências. Câmpus Universitário Darcy Ribeiro. Brasília/DF.
Emails: rayltoncarvalho@gmail.com; edbias@unb.br
Introdução
Área de estudo
Material e métodos
Materiais
Imagem
Pluviosidade
Pedologia
Declividade
Meio Social
Sofwares
Método
Modelagem
Análise multicritério
Estrutura do modelo
Modelagem em SIG
Meio físico
Geração do mapa de uso do solo
Resultados e Discussões
Mapa do nível de conservação ambiental da bacia do rio Melchior
Conclusões
Agradecimentos
Referências

\begin{abstract}
RESUMO - O presente trabalho teve como objetivo principal determinar o nível de conservação da bacia do Rio Melchior, DF, Brasil. Para isso, foi desenvolvido um modelo para identificação do nível de conservação dessa, com alternativas e critérios do meio físico e social. Os critérios e alternativas do modelo passaram por um processo de julgamento de pesos por meio do método multicritério Analytic Hierachy Process (AHP). Para auxiliar este método de avaliação e dos cálculos dos pesos atribuídos, foi utilizado o Software Expert Choice. Na elaboração do produto temático um mapa do nível de conservação utilizou a operação conhecida como álgebra de mapas, que faz uso de funções matemáticas com constante escalar ou o simples uso de uma operação aritmética. As operações algébricas com os mapas foram feitas de acordo com os pesos definidos e estabelecidos pelo AHP. Os resultados da integração do AHP e Sistema de Integração Geográfica (SIG) mostraram que as variáveis relacionadas ao meio físico (uso do solo, pluviosidade, pedologia e declividade) do meio social (água, esgoto e lixo) permitiram conhecer o Nível de Conservação Ambiental da Bacia. Dessa forma, as variáveis apresentadas no estudo foram eficientes para diagnosticar a fragilidade da bacia e fornecer indicativos para tomada de decisão.

Palavras-chave: Planejamento Ambiental; Método Multicritério; Sistema de Informação Geográfica; Ordenamento Territorial; Bacia Hidrográfica do Melchior.
\end{abstract}

\begin{abstract}
This study aimed to determine the basin conservation status of Rio Melchior, located in Brazil’s Federal District. In order to attain this goal, a model was developed to identify its level of preservation, using alternatives and standards of physical and social environment. The model's standards and alternatives went through a process of trial using the Analytic Hierarchy Process multi-criteria method (AHP). To assist this assessment method and the calculation of the assigned weights, the Software Expert Choice, was used. In preparing the thematic product, a map of the preservation status used the operation known as map algebra, which applies mathematical functions with constant climbing or the simple use of an arithmetic operation. Algebraic operations with maps were made according to the weights and measures established by AHP. The results of the integration of AHP and Geographic Integration System (GIS) showed that the variables related to the physical environment (land use, rainfall, soil conditions and slope), the social environment (water, sewer and garbage) provided the knowledge of the Basin Level of Preservation. Therefore, the variables presented in the study are efficient enough to diagnose the fragility of the basin and to provide evidence for making decisions.
\end{abstract}

Keywords: Environmental Planning; Multi-criteria method; Geographic Information System; Land Management; Melchior Watershed.

\section{INTRODUÇÃO}

Umas das principais bacias hidrográficas do Distrito Federal - DF é a do Rio Melchior, parte integrante da bacia do Rio Descoberto, que é responsável por $60 \%$ do abastecimento da água potável destinada ao consumo da população do
DF. A falta de planejamento tem produzido resultados desastrosos nas ações de gestão em bacias hidrográficas, o que tem gerado um avanço na degradação da qualidade ambiental e compromete o sucesso das ações de gestão 
neste setor. Isso se dá devido às ocupações irregulares do solo que aumentam exponencialmente junto com o crescimento do Distrito Federal - DF.

Essas ocupações ocorrem sem o devido planejamento e constituem ameaças ao meio ambiente, pois trazem consigo impactos negativos ao solo, água e ar.

Dos impactos mais visíveis em bacias hidrográficas, destacam-se: o desmatamento, os problemas com manejo do solo vinculados principalmente com os processos erosivos, controle da água, introdução de outras espécies sobre as nativas, aumento do crescimento demográfico e queimadas (Franco, 2009).

O planejamento ambiental tem como um de seus objetivos a aplicação das políticas voltadas ao uso dos recursos hídricos, de forma a garantir as condições ecológicas para o desenvolvimento efetivo da produção social, e todas as atividades da população, do uso racional e da proteção dos recursos do meio ambiente (Peixoto, 2005; Novais, 2011). Dessa forma, as realizações de estudos com foco no planejamento ambiental das bacias hidrográficas servem de subsídio para conhecer as suas fragilidades e fornecer indicativos para a tomada de decisão no âmbito do processo de planejamento e de gestão territorial.

Tendo como base a análise da qualidade ambiental, o presente trabalho tem como objetivo geral avaliar os impactos ambientais na bacia do Rio Melchior, visando o seu ordenamento ambiental.

\section{ÁREA DE ESTUDO}

O estudo foi realizado na bacia do Rio Melchior (Figura 1) localizado entre as longitudes $48^{\circ} 02^{\prime} 30^{\prime \prime} \mathrm{W}$ e latitudes $15^{\circ} 48^{\prime} \mathrm{S}$ e longitudes $48^{\circ} 15^{\prime} 21$ ”'W e latitudes $15^{\circ} 55^{\prime} 17$ 's, ocupando uma área de 207,8 km².

O rio Melchior é formado a partir da confluência do Ribeirão Taguatinga com o
Córrego do Valo e o Córrego Gatumé, entre as cidades satélites de Ceilândia e Samambaia, dentro da área de relevante interesse ecológico Juscelino Kubitscheck, a 983 metros de altitude. Ele, o rio Melchior, corre no sentido NordesteSudoeste até desaguar no Rio Descoberto, percorrendo cerca de $30 \mathrm{Km}$.

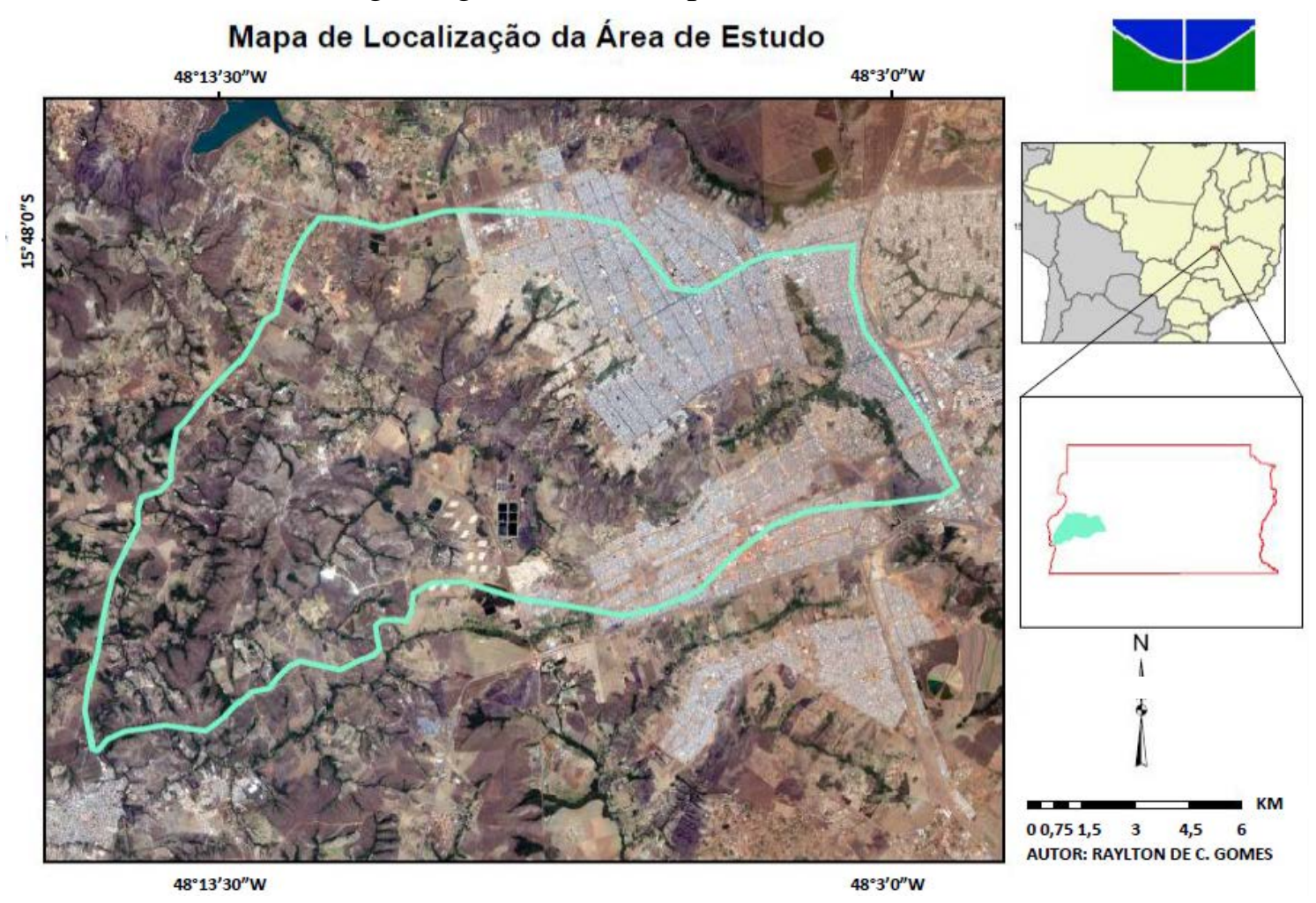

Figura 1 - Delimitação e imagem da área de estudo.

\section{MATERIAL E MÉTODOS}

\section{Materiais Imagem}

Foi utilizada uma imagem RapidEye na elaboração do mapa de uso e ocupação do solo, obtidas por meio de uma parceria do MMA e o Instituto Geociências. 


\section{Pluviosidade}

O mapa de isoietas foi desenvolvido por Gonçalves (2007), e gerado a partir de um banco de estações climatológicas e pluviômetros existentes no Distrito Federal, com dados coletados no período de 1960 a 2006, o mapa foi recortado e adaptado para bacia do Melchior utilizando o software ArcGIS 10.2.

\section{Pedologia}

O mapa pedológico foi desenvolvido pela Embrapa (2004a) e adaptado para bacia do Melchior utilizando o software ArcGis 10.2.

\section{Declividade}

$\mathrm{Na}$ elaboração do mapa de declividade foram utilizadas as curvas de nível da base de dados topográficos planialtimétricos do Sistema Cartográfico do Distrito Federal na escala original de 1:10.000 disponibilizada pela CODEPLAN (1992).

\section{Meio Social}

Para caracterização do meio social residente na bacia Hidrográfica do Rio Melchior foi realizado o levantamento de dados junto ao censo demográfico 2010, do Instituto Brasileiro de Geografia e Estatística - IBGE.

\section{Sofwares}

Foram utilizados os seguintes programas para desenvolvimento da presente pesquisa: ArcGIS 10.2 (ESRI, 2013); Expert Choice 11 (EXPERT CHOICE RESOURCE ALIGNER, 2004)

\section{Métodos}

\section{Modelagem}

Pode-se encontrar na literatura nacional e internacional diversos modelos com aplicações multidisciplinares (análise de água, poluição do solo, entre outros), no entanto será descrito o modelo de análise multicritério que pode ser aplicado a temas relacionados a conservação ambiental.

\section{Análise Multicritério}

A partir da década de 70 foi desenvolvido por Tomas L. Saaty o método AHP (Analytic Hierarchy Process), um dos métodos multicritérios mais conhecido e utilizado no auxílio nas tomadas de decisões mais complexas. Este método auxilia de forma mais compreensiva a criação de hierarquias, critérios e metas. Após a criação da hierarquia, os responsáveis pela decisão podem avaliar sistematicamente seus elementos, por meio de comparações.

Segundo Costa (2004) o método AHP se baseia em três princípios do pensamento analítico:

\section{Construção de hierarquias:}

No AHP o problema é estruturado em níveis hierárquicos, como forma de buscar uma melhor compreensão e avaliação do mesmo. Na definição das hierarquias o nível 1 deve ser formado pelo objetivo principal, no caso da presente pesquisa medir o nível de conservação ambiental da bacia do rio Melchior e o nível 2 e 3 formados pelos critérios e alternativas definidas pelo responsável pela pesquisa, ou seja, medir o nível de conservação do meio físico e social da bacia do rio Melchior (Figura 2).

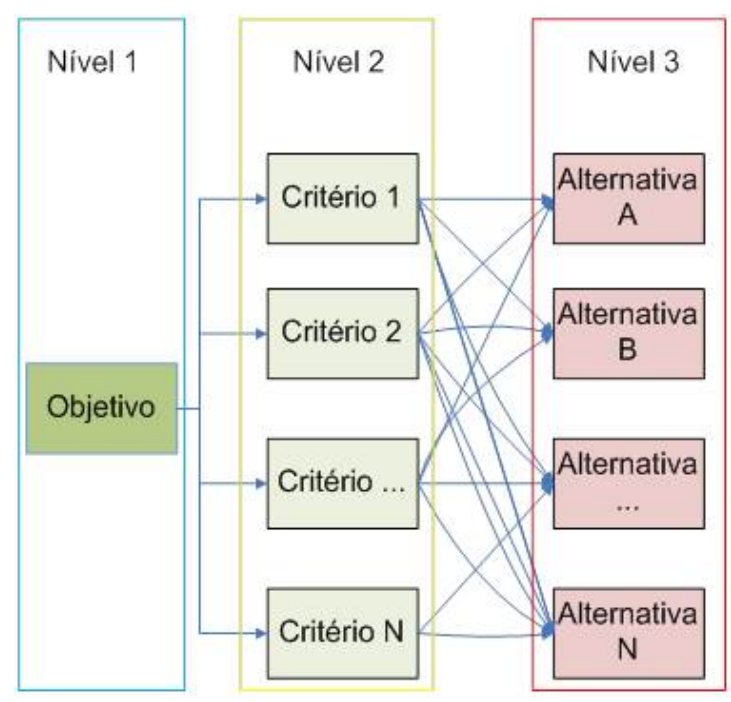

Figura 2 - Estruturação hierárquica do AHP.

Ainda segundo Costa (2004), a construção de hierarquias é uma etapa fundamental do processo de raciocínio lógico, identificando- se os elementos chave para a tomada de decisão, agrupando-os em conjuntos afins formando as alternativas. 
II. Definição de prioridades:

$\mathrm{O}$ ajuste das prioridades no AHP fundamenta-se na habilidade do ser humano de perceber o relacionamento entre os objetos e as situações observadas, comparando-as duas-aduas, à luz de um determinado foco, critério ou julgamentos paritários e, posteriormente conectando-os em um nível superior, compondo as matrizes de julgamento (Costa, 2004). Os pesos são definidos individualmente por cada pesquisador que participa da avaliação, obedecendo à hierarquia definida. A escala numérica de pesos varia de 1 a 9 , conforme tabela 1.

Tabela 1 - Descrição dos pesos.

\begin{tabular}{l|l}
\hline Peso & Descrição \\
\hline $\mathbf{1}$ & Extra baixo-elementos de igual importância \\
\hline $\mathbf{2}$ & Muito baixo \\
\hline $\mathbf{3}$ & Baixo - importância moderada de um dos elementos sobre o outro \\
\hline $\mathbf{4}$ & Pouco baixo \\
\hline $\mathbf{5}$ & Médio - forte importância de um elemento sobre o outro \\
\hline $\mathbf{6}$ & Pouco alto \\
\hline $\mathbf{7}$ & Alto - importância muito forte de um elemento sobre o outro \\
\hline $\mathbf{8}$ & Muito alto \\
\hline $\mathbf{9}$ & Extra alto - extrema importância de um elemento sobre o outro \\
\hline
\end{tabular}

$$
\mathrm{A}=\left[\begin{array}{cccc}
1 & \mathrm{a}_{12} & \ldots & \mathrm{a}_{1 \mathrm{n}} \\
1 / \mathrm{a}_{21} & 1 & \ldots & \mathrm{a}_{2 \mathrm{n}} \\
& & \ldots & \ldots \\
1 / \mathrm{a}_{\pi 1} & 1 / \mathrm{a}_{\pi 2} & \ldots & 1
\end{array}\right]
$$

Figura 3 - Matriz de julgamento.

Segundo Marins et al. (2009) a quantidade de julgamentos necessários para a construção de uma matriz de julgamentos genérica $A$ é $n$ (n-1) $/ 2$, onde $n$ é o número de elementos pertencentes a esta matriz. Os elementos A são definidos pelas condições descritas na figura 3 .

A normalização das matrizes de julgamento é dada pelo somatório dos elementos de cada coluna e posteriormente pela divisão de cada elemento pelo somatório dos valores de cada coluna.

\section{Consistência lógica}

Segundo Costa (2004) no AHP é possível avaliar a consistência do modelo de priorização construído.

Essa avaliação é realizada pelo valor do índice de inconsistência, dado por IC = (Ymáx $n) /(n-1)$, onde Ymáx é o maior autovalor da matriz de julgamentos (Costa, 2004).

De acordo com Saaty (1991) os valores têm que ser menores ou iguais a 0,10 para assegurar uma lógica racional no processo.

Foi utilizado o Software Expert Choice versão 3.01 (EXPERT CHOICE RESOURCE Aligner, 2004) no auxílio do processo de julgamento e dos cálculos dos pesos atribuídos.

\section{Estrutura do modelo}

Com base nas literaturas nacionais e internacionais (Martins et al., 2005; Sánchez, 2008; Xavier, 2011; Novais, 2011; Silva et al., 2007, 2011; Zaidan, 2011; Sharafi et al., 2012; Bernardi et al., 2013; Reis et al., 2013; Zhao et al., 2013; Zhou et al., 2014), foi desenvolvido um modelo para identificação do nível de conservação ambiental da bacia hidrográfica do Melchior (Figura 4).

Os critérios elencados na figura 4 passaram por um processo de julgamento de pesos, sendo dividido em três etapas: na primeira etapa foram julgados os dados das subdivisões das divisões do meio físico e social, na segunda etapa foram julgadas as subdivisões do meio físico e social e já na terceira etapa foi julgado o meio físico e social (Figura 4).

Esse julgamento foi realizado por meio do 
método multicritério Analytic Hierarchy Process (AHP), por 5 (cinco) pesquisadores e em seguida, o resultado do julgamento passou por um processo de modelagem em SIG.

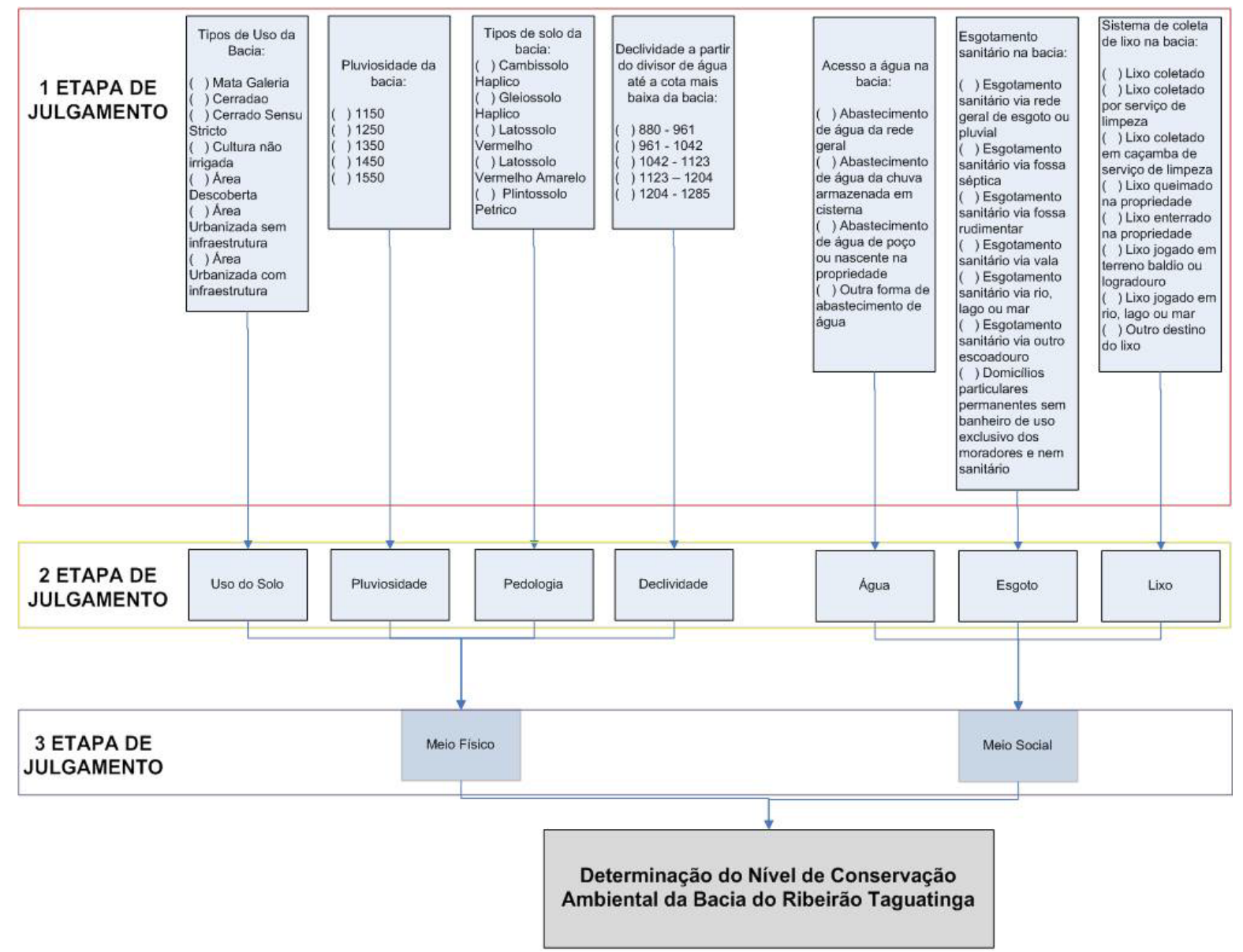

Figura 4 - Modelo para identificação do nível de conservação ambiental da bacia do Rio Melchior

\section{Modelagem em SIG}

$\mathrm{Na}$ elaboração do mapa do nível de conservação ambiental da bacia do Melchior os shapefiles de declividade, classificação do uso do solo, pluviosidade, pedologia, declividade, água, esgoto e resíduos sólidos, foram convertidos para o formato raster e reclassificados com base nos pesos que determinaram a influência de cada um dos elementos na análise da qualidade ambiental, ranqueando os pesos definidos pelos pesquisadores.

Após essa etapa os dados de Classificação do uso do solo, pluviosidade, pedologia, declividade foram multiplicados pelos pesos, obtidos no processo de julgamento, e, depois, integrados utilizando a ferramenta Raster Calculator, gerando o Mapa de integração do meio físico.
O mesmo procedimento foi empregado para o meio social.

Por fim, os mapas de integração do meio físico e do meio social, foram integrados por meio da ferramenta Raster Calculator utilizando-se os pesos relativos, gerados pelo AHP gerando o Mapa do Nível de Conservação Ambiental da Bacia do Melchior.

\section{Meio Físico}

Geração do Mapa de Uso do Solo

Após a aquisição da imagem foi realizada a composição colorida com as bandas 3(R), 2(G) e 1(B) do Sensor Multiespectral (pushbroom imager). A construção do mapa de uso do solo foi baseado na técnica de digitalização HeadsUp, utilizando o software ArcGIS 10.2, e a imagem RapidEye como background.

\section{RESULTADOS E DISCUSSÕES}

Neste capítulo são apresentados e analisados os resultados obtidos na aplicação da metodologia proposta para a presente pesquisa.

A figura 5 apresenta todos os critérios, as alternativas e a média dos pesos definidos pelos pesquisadores utilizando o método AHP, para realização do pareamento das alternativas e critérios para elaboração dos mapas temáticos. 
$\mathrm{Na}$ terceira etapa de julgamento dos pesos, ou seja, a fase em que se define o peso relativo que o meio físico e o social exercem na análise proposta para a bacia, o meio físico desempenhou $75 \%$ de influência no nível de conservação ambiental em comparação com o meio social, fatores como o uso do solo, pluviosidade, declividade e pedologia representam maior influência do que a gestão da água, esgoto e o lixo em bacias hidrográficas.

Este resultado vem ao encontro dos estudos realizados por Ribeiro (2001), que identificou que o uso do solo tem grande contribuição na poluição e autodepuração nos rios Melchior e Descoberto, a partir de modelos matemáticos de simulação da qualidade da água.

Dentro do uso do solo pode-se destacar a ocupação urbana com e sem infraestrutura, pois ela desempenha o maior nível de degradação ambiental, favorecendo o aumento do peso do meio físico encontrado no estudo. Já o meio social, teve menor peso, exercendo $25 \%$ de influência no nível de conservação ambiental, comprovando a situação real de parte da área de estudo, onde, identifica-se a deficiência no tratamento de efluentes, abastecimento de água (existência de muitas cisternas, poços) e no gerenciamento de resíduos sólidos.

$\mathrm{Na}$ terceira etapa de julgamento dos pesos, ou seja, a fase em que se define o peso relativo que o meio físico e o social exercem na análise proposta para a bacia, o meio físico desempenhou $75 \%$ de influência no nível de conservação ambiental em comparação com o meio social, fatores como o uso do solo, pluviosidade, declividade e pedologia representam maior influência do que a gestão da água, esgoto e o lixo em bacias hidrográficas.

\begin{tabular}{|c|c|c|c|c|c|}
\hline $\begin{array}{l}3 \text { Etapa de } \\
\text { Julgamento }\end{array}$ & 2 Etapa de Julgamento & 1 Etapa de Julgamento & $\begin{array}{l}3 \text { Etapa de } \\
\text { Julgamento }\end{array}$ & 2 Etapa de Julgamento & 1 Etapa de Julgamento \\
\hline \multirow{21}{*}{$\begin{array}{l}\text { Meio Fisico } \\
(p=0,667)\end{array}$} & \multirow{7}{*}{$\begin{array}{l}\text { Uso do Solo } \\
(p=0,692)\end{array}$} & $\begin{array}{l}\text { Área Urbanizada sem infraestrutura } \\
\qquad(p=0,418)\end{array}$ & \multirow{21}{*}{$\begin{array}{l}\text { Meio social } \\
(p=0,333)\end{array}$} & \multirow{7}{*}{$\begin{array}{c}\text { Esgoto } \\
(p=0,429)\end{array}$} & $\begin{array}{l}\text { Domicilios particulares permanentes sem banheiro } \\
\qquad(p=0,366)\end{array}$ \\
\hline & & $\begin{array}{l}\text { Área Urbanizada com infraestrutura } \\
\qquad(p=0,220)\end{array}$ & & & $\begin{array}{l}\text { Esgotamento sanitário via outro escoadouro } \\
\qquad(p=0,200)\end{array}$ \\
\hline & & $\begin{array}{l}\text { Área Descoberta } \\
(p=0,144)\end{array}$ & & & $\begin{array}{l}\text { Esgotamento sanitário via rio, lago ou mar } \\
\qquad(p=0,148)\end{array}$ \\
\hline & & $\begin{array}{l}\text { Cultura não irrigada } \\
\qquad(p=0,078)\end{array}$ & & & $\begin{array}{l}\text { Esgotamento sanitário via vala } \\
\qquad(p=0,108)\end{array}$ \\
\hline & & $\begin{array}{l}\text { Cerrado Sensu Stricto } \\
\qquad(p=0,059)\end{array}$ & & & $\begin{array}{l}\text { Esgotamento sanitário via fossa rudimentar } \\
\qquad(p=0,074)\end{array}$ \\
\hline & & $\begin{array}{l}\text { Cerradão } \\
(0,046)\end{array}$ & & & $\begin{array}{l}\text { Esgotamento sanitário via rede geral de esgoto ou } \\
\text { pluvial } \\
(p=0,052)\end{array}$ \\
\hline & & $\begin{array}{l}\text { Mata de Galeria } \\
(p=0,035)\end{array}$ & & & $\begin{array}{l}\text { Esgotamento sanitário via fossa séptica } \\
\qquad(p=0,052)\end{array}$ \\
\hline & & $\begin{array}{c}1550 \\
(\mathbf{p}=\mathbf{0}, \mathbf{3 2 3})\end{array}$ & & \multirow{8}{*}{$\begin{array}{c}\quad \operatorname{LixO} \\
(p=0,429)\end{array}$} & $\begin{array}{l}\text { Outro destino do lixo } \\
(p=0,322)\end{array}$ \\
\hline & & $\begin{array}{c}1450 \\
(p=0,262)\end{array}$ & & & $\begin{array}{l}\text { Lixo jogado em rio, lago ou mar } \\
(p=0,218)\end{array}$ \\
\hline & $\begin{array}{l}\text { Pluviosidade } \\
(p=0,154)\end{array}$ & $\begin{array}{c}1350 \\
(p=0,185)\end{array}$ & & & $\begin{array}{l}\text { Lixo jogado em terreno baldio ou logradouro } \\
\qquad(p=0,143)\end{array}$ \\
\hline & & $\begin{array}{c}1250 \\
(p=0,128)\end{array}$ & & & $\begin{array}{l}\text { Lixo enterrado na propriedade } \\
\qquad(p=0,085)\end{array}$ \\
\hline & & $\begin{array}{c}1150 \\
(p=0,102)\end{array}$ & & & $\begin{array}{l}\text { Lixo queimado na propriedade } \\
(p=0,085)\end{array}$ \\
\hline & \multirow{5}{*}{ Declividade $(p=0,080)$} & $\begin{array}{c}>20 \% \\
(p=0,419)\end{array}$ & & & $\begin{array}{l}\text { Lixo coletado em caçamba de serviço de limpeza } \\
(p=0,049)\end{array}$ \\
\hline & & $\begin{array}{l}10-20 \% \\
(p=0,263)\end{array}$ & & & $\begin{array}{l}\text { Lixo coletado por serviço de limpeza } \\
\qquad(\mathbf{p = 0 , 0 4 9 )}\end{array}$ \\
\hline & & $\begin{array}{c}5-10 \% \\
(p=0,160)\end{array}$ & & & $\begin{array}{l}\text { Lixo coletado } \\
(p=0,049)\end{array}$ \\
\hline & & $\begin{array}{c}2-5 \% \\
(p=0,096)\end{array}$ & & \multirow{6}{*}{$\begin{array}{c}\text { Água } \\
(p=0,142)\end{array}$} & $\begin{array}{l}\text { Outra forma de abastecimento de água } \\
\qquad(p=0,424)\end{array}$ \\
\hline & & $\begin{array}{c}0-2 \% \\
(p=0,062)\end{array}$ & & & \multirow{2}{*}{$\begin{array}{l}\text { Abastecimento de água de poço ou nascente na } \\
\text { propriedade } \\
\text { ( } \mathbf{p}=\mathbf{0 , 2 2 7 )}\end{array}$} \\
\hline & \multirow{4}{*}{$\begin{array}{l}\text { Pedologia } \\
(p=0,074)\end{array}$} & $\begin{array}{l}\text { Gleissolo Haplico } \\
(p=0,384)\end{array}$ & & & \\
\hline & & $\begin{array}{c}\text { Cambissolo Háplico } \\
\quad(\mathbf{p}=\mathbf{0 , 1 7 8 )} \\
\text { Latossolo Vermelho Amarelo }\end{array}$ & & & $\begin{array}{l}\text { Abastecimento de água da chuva armazenada em } \\
\text { cisterna } \\
(\mathbf{p}=\mathbf{0 , 2 2 7 )}\end{array}$ \\
\hline & & Latossolo Vermelho & & & \multirow{2}{*}{$\begin{array}{l}\text { Abastecimento de água de rede geral } \\
\qquad(p=0,122)\end{array}$} \\
\hline & & $\begin{array}{l}(p=0,087) \\
\text { Plintossolo Petrico } \\
(p=0,230)\end{array}$ & & & \\
\hline
\end{tabular}

Figura 5 - Resultado do julgamento de pesos.

Este resultado vem ao encontro dos estudos realizados por Ribeiro (2001), que identificou que o uso do solo tem grande contribuição na poluição e autodepuração nos rios Melchior e Descoberto, a partir de modelos matemáticos de simulação da qualidade da água.

Dentro do uso do solo pode-se destacar a ocupação urbana com e sem infraestrutura, pois ela desempenha o maior nível de degradação ambiental, favorecendo o aumento do peso do meio físico encontrado no estudo.

Já o meio social, teve menor peso, exercendo 25\% de influência no nível de conservação ambiental, comprovando a situação real de 
parte da área de estudo, onde, identifica-se a deficiência no tratamento de efluentes, abastecimento de água (existência de muitas cisternas, poços) e no gerenciamento de resíduos sólidos.

No meio físico, o uso do solo exerce $69,2 \%$ de influência, sendo assim, o que mais impacta a qualidade ambiental da bacia, sobrepondo-se à pluviosidade, declividade e pedologia.

Os valores obtidos são confirmados quando se analisa a realidade da bacia, pois em diversos locais encontram-se a falta de infraestrutura, falta de direcionamento da água, falta de coleta de esgoto, falta de água potável, grandes áreas impermeáveis, entre outros, dados que são apresentados por autores como Callisto et al. (2002) que propôs um protocolo de avaliação rápida da diversidade de habitats como ferramenta em atividades de ensino, gestão e pesquisa.

Aspectos como a pluviosidade, declividade e uso do solo podem influenciar na disponibilidade e a qualidade dos recursos naturais, provocar perda da biodiversidade, queda na fertilidade do solo, intensificação dos processos erosivos, poluição das águas, além de afetar a biodiversidade em toda a bacia. Mendoza et al. (2011) analisou o processo de mudança de cobertura da terra ao longo de um período de tempo e observou que o uso do solo, declividade e pluviosidade influencia na disponibilidade e qualidade dos recursos naturais, vindo ao encontro dos resultados obtidos na presente pesquisa.

Para a implementação do Mapa da Conservação do Meio Físico, foram integrados os produtos referentes ao uso do solo, pluviosidade, Declividade e Pedologia, sendo representados pelas figuras $6,7,8$ e 9 .

A figura 6 define o Mapa do Uso do Solo, que apresenta os percentuais para cada classe de uso indicados na tabela 2.

Tabela 2 - Classes, peso e porcentagem do uso do solo na Bacia.

\begin{tabular}{l|l|l}
\multicolumn{1}{c|}{ Classe } & Peso & \% na Bacia \\
\hline Área urbanizada sem infraestrutura & 0,418 & 6 \\
\hline Área urbanizada com infraestrutura & 0,220 & 25 \\
\hline Área descoberta & 0,200 & 3 \\
\hline Cultura não irrigada & 0,108 & 4 \\
\hline Cerrado Sensu Stricto & 0,079 & 49 \\
\hline Cerradão & 0,061 & 1 \\
\hline Mata de galeria & 0,044 & 12 \\
\hline
\end{tabular}
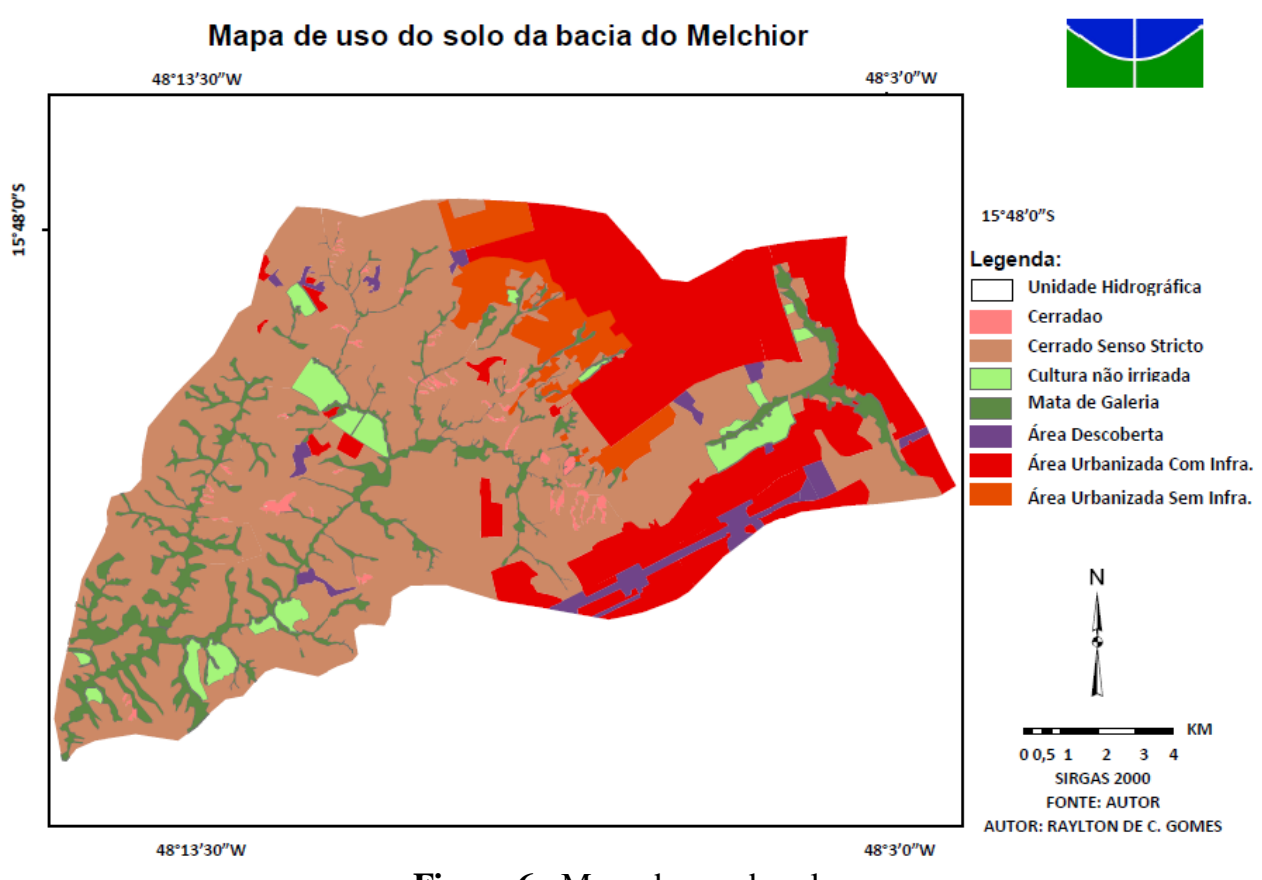

Figura 6 - Mapa de uso do solo. 
A análise do uso e ocupação do solo na Bacia do Melchior, demonstrou que as áreas urbanizadas com e sem infraestrutura e descobertas tem sua grande extensão a nordeste e a sudeste da bacia, cobrindo cerca de 34\% da área total. São nessas áreas que estão localizadas as mais populosas cidades satélites do DF, como Samambaia, Taguatinga e Ceilândia, contabilizando em torno de 600.000 habitantes.

Já os demais $66 \%$ da bacia, compreendendo as áreas sudoeste e noroeste, são ocupadas por
Cerrado Senso Stricto, a Mata de galeria, Cerradão e as culturas não irrigadas.

Já o fator de pluviosidade (Figura 7) foi analisado em função da relação existente com os processos de transporte de diversos materiais, além dos sedimentos para as áreas mais baixas do terreno, chegando aos corpos hídricos e intensificando os processos assoreamento e, reduzindo os valores de nutrientes disponíveis no solo. Os valores foram tabulados de acordo com a tabela 3.

Tabela 1 - Classes, peso e porcentagem da pluviosidade na bacia

\begin{tabular}{l|l|l}
\hline Classe & Peso & \% na Bacia \\
\hline $\mathbf{1 1 5 0}$ & 0,418 & 6 \\
\hline $\mathbf{1 2 5 0}$ & 0,220 & 25 \\
\hline $\mathbf{1 3 5 0}$ & 0,200 & 3 \\
\hline $\mathbf{1 4 5 0}$ & 0,108 & 4 \\
\hline $\mathbf{1 5 5 0}$ & 0,079 & 49 \\
\hline
\end{tabular}

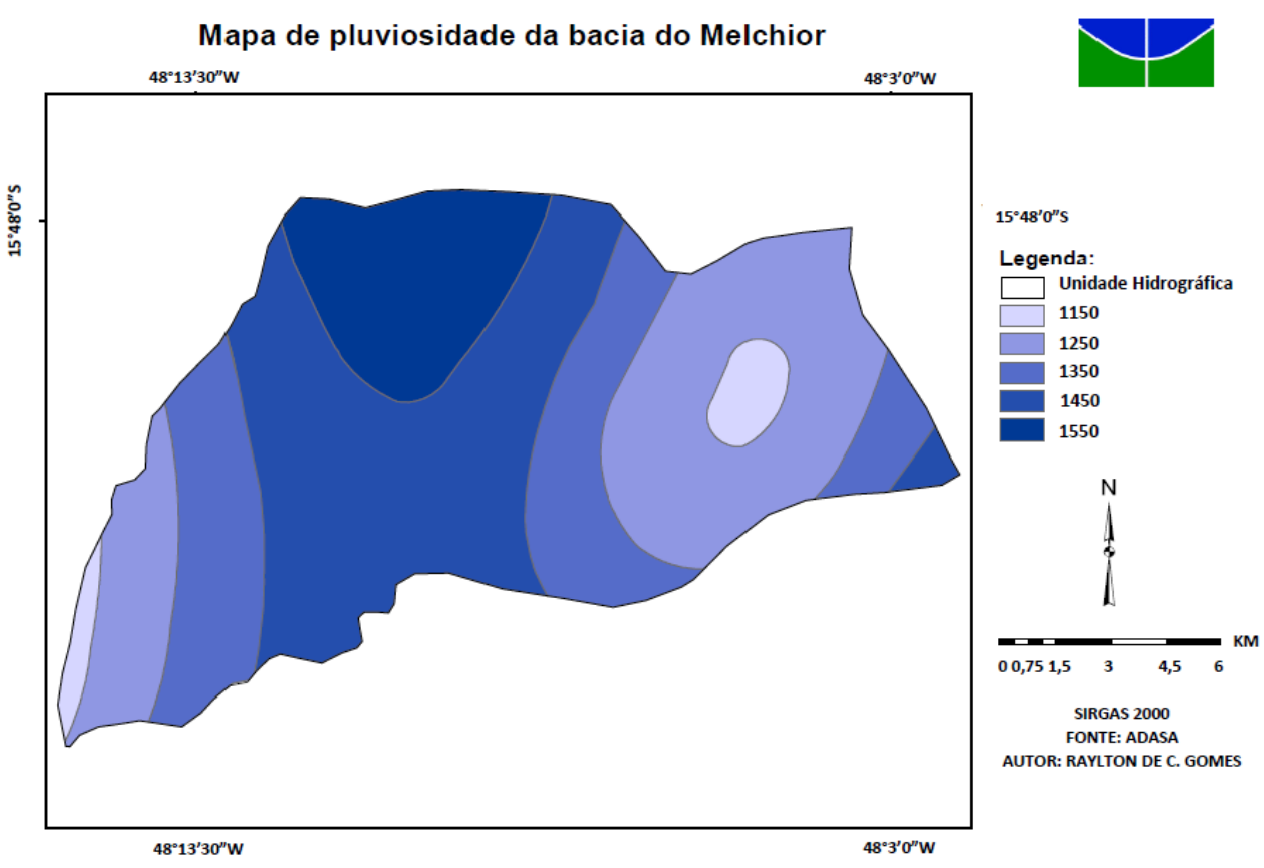

Figura 7 - Mapa de pluviosidade da bacia do Melchior.

Na figura 8 do mapa de declividade e na tabela 5 podem-se analisar os seguintes aspectos da bacia: A classe de maior impacto é a que representa a declividade $>20 \%$, mas, com uma representatividade baixa (menos de $2 \%$ ), já a de menor impacto encontra-se na classe de $0-2 \%$, sendo a de menor peso e com uma maior representatividade na bacia com $44 \%$.

A declividade de uma bacia hidrográfica tem relação com vários processos hidrológicos, tais como a infiltração, o escoamento superficial.
Estudos desenvolvidos por Piroli e Campos, (2009) sugerem que as declividades superiores a $20 \%$ sejam ocupadas por atividades menos agressivas ao solo como, por exemplo, reflorestamento.

Analisando-se o mapa de pedologia, figura 9 , observa-se que $60 \%$ da bacia possui os solos do tipo latossólico, 38\% o câmbico, mantendo a proporcionalidade existente para a área do Distrito Federal que é de 54,50\% e 30,98\%, respectivamente (EMBRAPA, 2004). 
Tabela 4 - Classes, peso e porcentagem da pluviosidade na bacia

\begin{tabular}{l|l|l}
\hline Classe & Peso & \% na Bacia \\
\hline $\mathbf{0 - 2}$ & 0,419 & 44 \\
\hline $\mathbf{2 - 5}$ & 0,263 & 30 \\
\hline $\mathbf{5 - 1 0}$ & 0,160 & 16 \\
\hline $\mathbf{1 0 - 2 0}$ & 0,096 & 8 \\
\hline $\mathbf{> 2 0}$ & 0,062 & 2 \\
\hline
\end{tabular}

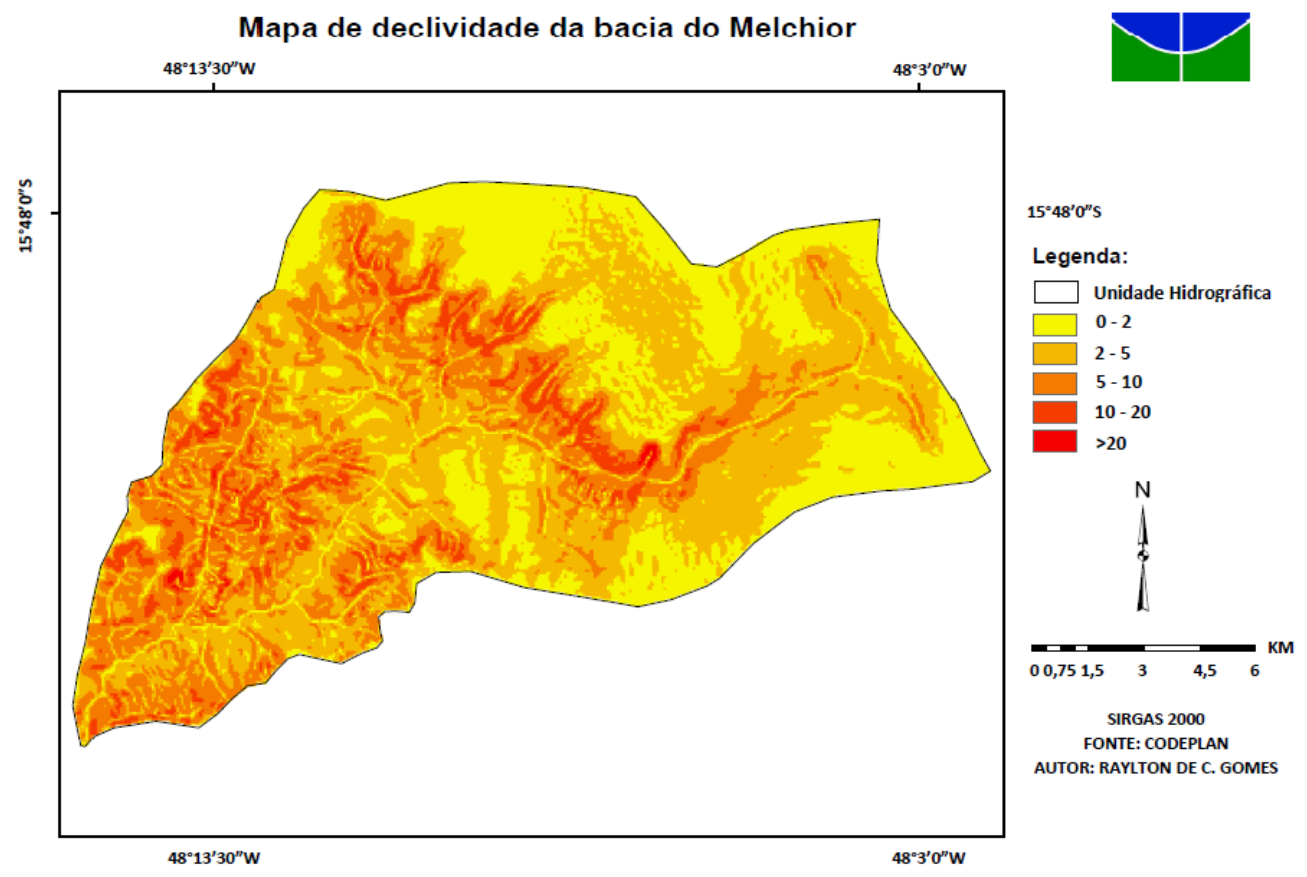

Figura 8 - Mapa de declividade da bacia do Melchior.

A tabela 5 apresenta os tipos de solo e as suas respectivas porcentagens na bacia.

A influência dos pesos dos especialistas e consequentemente a classificação do AHP, posicionando a pedologia com o menor peso, reflete bem a realidade da bacia, em razão dos seus índices de declividade, pois como pode-se constatar, 74\% da bacia encontra-se na faixa de declividade de 0 a $5 \%$, caracterizando relevos plano e suave-ondulados.

Os resultados estão em consonância com os estudos de Lopes \& Pejon (2001), Ribeiro \& Salomão (2001), Silva et al., (2007) que descrevem a relação entre a declividade e solo, definindo que em áreas mais planas encontram-se os solos mais intemperizados e mais velhos, portanto mais desenvolvidos e, em locais com menor declividade ocorrem os solos mais jovens.

Tabela 5 - Classes, peso e porcentagem dos tipos de solo na bacia

\begin{tabular}{l|l|c}
\multicolumn{1}{c|}{ Tipo de solo } & Peso & \% na Bacia \\
\hline Plintossolo Petrico & 0,384 & 0,8 \\
\hline Latossolo vermelho-amarelo & 0,178 & 4 \\
\hline Latossolo vermelho & 0,121 & 56 \\
\hline Gleissolo Háplico & 0,087 & 1,2 \\
\hline Cambissolo Háplico & 0,230 & 38 \\
\hline
\end{tabular}

O mapa de integração do meio físico, figura 10, foi obtido a partir da integração dos dados do meio físico.

Da figura 10 pode-se analisar os seguintes aspectos: $12 \%$ da área foi classificada com o nível de conservação muito alta, 23\% alta, 33\% média, $16 \%$ baixa e $16 \%$ nula.

Observa-se que a área com maior nível (alta 
e muito alta) de conservação, encontra-se margeando ou próximo às redes de drenagem, portanto, pode-se deduzir que a mesma seja de Mata de Galeria que recebeu o menor peso por parte dos especialistas tento menor fragilidade, significando que possui a maior influência na qualidade ambiental.

Contrariamente, deve-se ter maior preocupação com as áreas de conservação classificadas como nulo e baixo níveis de conservação, que estão localizadas em sua grande maioria nas áreas urbanizadas.

Verificou-se que as áreas urbanizadas sem a correta infraestrutura, representando $6 \%$ de participação na bacia, ocupa uma área de 12,5 $\mathrm{km}^{2}$. Vale destacar que essas áreas têm pequena representatividade na bacia, localizadas na parte nordeste das áreas urbanizadas, onde se encontra as ocupações irregulares do solo.

Da área da bacia 25\%, representando $51,9 \mathrm{~km}^{2}$, são de áreas urbanizadas com infraestrutura consolidada, ou seja, possuem orientação das águas pluviais, asfalto, rede de água, de luz e de esgotamento sanitário. Esta área incorpora as cidades satélites de Ceilândia, Samambaia e Taguatinga. Possuindo maior representatividade no mapa de uso do solo, e menor peso, assumindo menor influência no nível de conservação ambiental que áreas urbanizadas sem infraestrutura. A definição dos pesos pelos especialistas e a avaliação do AHP, demonstraram um grau de dependência entre as variáveis da seguinte forma: a pedologia sofre influência da declividade e da pluviosidade, à medida que ocorre um maior índice pluviométrico. Este resultado vem ao encontro dos estudos apresentados por Lopes \& Pejon, (2001), que demonstraram, por meio da interação destes fatores, a influência dos mesmos na geração de processos erosivos, e consequentemente, influenciando os níveis de qualidade ambiental. Lopes \& Pejon, (2001), utilizou uma série de atributos do meio físico, como geologia, pedologia, materiais inconsolidados, declividade e CEMPAS (Carta de Extensão do Menor Percurso da Água Superficial), representados na escala 1:50.000, na elaboração das cartas de Susceptibilidade à Erosão do Rio Passa Cinco, com base no Sistema de Informação Geográfica IDRISI.

Na análise do meio social, os dois aspectos que obtiveram os maiores pesos foram os resíduos sólidos, a coleta e destinação de esgoto, representando respectivamente $85,8 \%$ e a classe que apresentou a menor influência foi à água com $14,2 \%$.

Os valores encontrados refletem bem a realidade do que ocorre em $6 \%$ da bacia do Rio Melchior, principalmente, enı ıdzau ud forma como é feito o descarte irregular de residuos sólidos e o processo de coleta e destinação do esgoto, demonstrando a deficiência de saneamento nesta região.

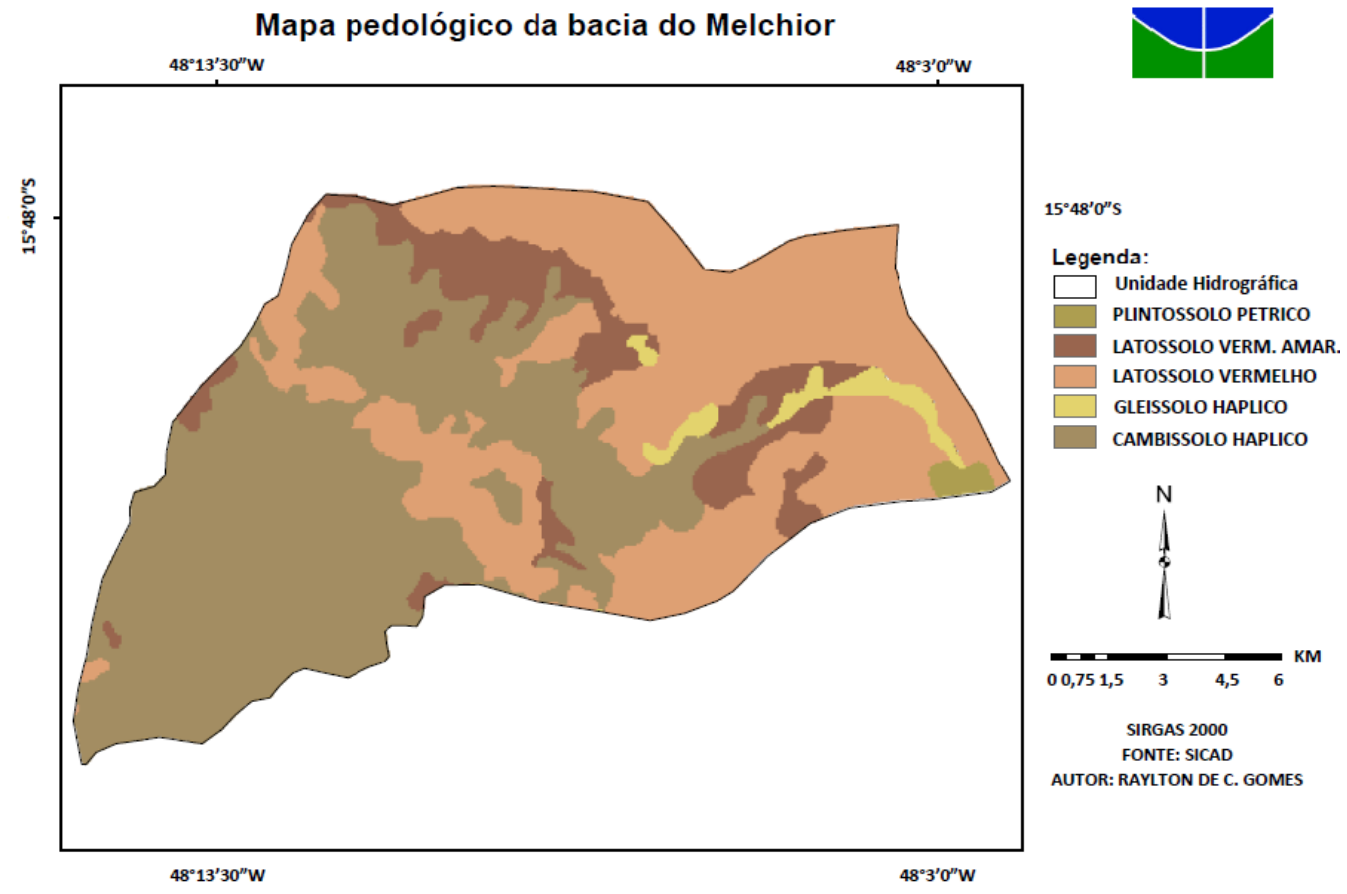

Figura 9 - Mapa pedológico da bacia do Melchior. 


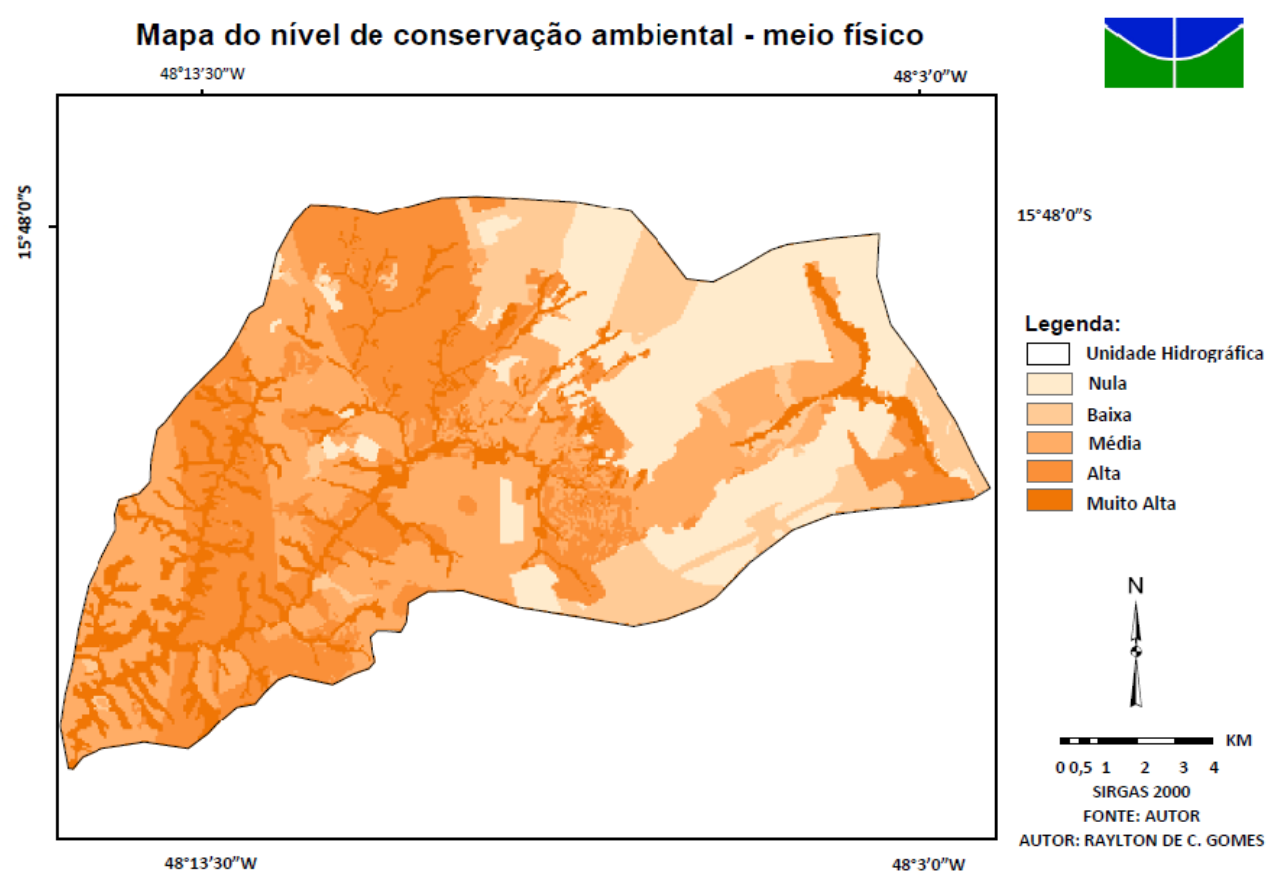

Figura 10 - Mapa de integração dos dados do meio físico.

O menor peso na classificação do AHP foi para o fator água. O posicionamento na classificação também reflete a realidade dos 6\% localizado na porção nordeste/sudeste da bacia, que não possui na sua totalidade sistema de distribuição de água, sendo necessário o uso de cisternas e poços. Já, as áreas urbanizadas com infraestrutura representando $25 \%$ da bacia possui atendimento pela CAESB - Companhia de Saneamento Ambiental do DF. Observa-se que os outros $69 \%$ da bacia, totalizando $143,4 \mathrm{~km}^{2}$, representados pelas áreas rurais utilizam poços para o seu abastecimento de água e o esgotamento sanitário é feito em fossas sépticas, conforme ocorre em todas as áreas rurais de outras localidades do DF e do Brasil, dado o custo e a inviabilidade da construção de redes de água e coleta de esgoto.

Objetivando gerar o mapa de conservação do meio social, foram integrando os temas relacionados na etapa 1 do julgamento. Todos os temas foram normalizados para o mesmo número de classes e as figuras dos temas que compuseram o produto, são apresentadas nas figuras 11, 12 e 13. A figura 14 apresenta a integração dos dados do meio social.

Para composição do tema Esgoto (representado na Figura 11), foram utilizados dados de 7 (sete) produtos: Domicílios particulares permanentes sem banheiro,
Esgotamento sanitário via outro escoadouro, Esgotamento sanitário via rio, lago ou mar, Esgotamento sanitário via vala, Esgotamento sanitário via fossa rudimentar, Esgotamento sanitário via rede geral de esgoto ou pluvial e Esgotamento sanitário via fossa séptica, obtidos da base do censo do IBGE (2010).

Analisando os resultados demonstrados no mapa de integração dos dados do esgotamento sanitário (Figura 11) é possível inferir que as áreas a noroeste da bacia, cujo adensamento urbano é mais significativo há o predomínio do esgotamento sanitário via rede geral de esgoto ou pluvial e do esgotamento via fossa séptica.

Os métodos utilizados para coleta do esgoto em áreas urbanas demonstram ser mais eficazes, e com isso, esses desempenham menor influência em impactos ambientais causados na bacia em questão, apontando para a efetividade dos pesos definidos pelos especialistas e para estruturação do modelo AHP.Já ao sudeste da bacia onde prevalecem as áreas rurais, verifica-se que há um número maior de domicílios com esgotamento sanitário destinado via outro escoadouro e fossas rudimentares, esses são os principais responsáveis pelo impacto provocado pelos esgotos sanitários, sem tratamento, lançados no córrego Melchior ou em solo, estando em consonância com os dados demostrados pelo Censo. 


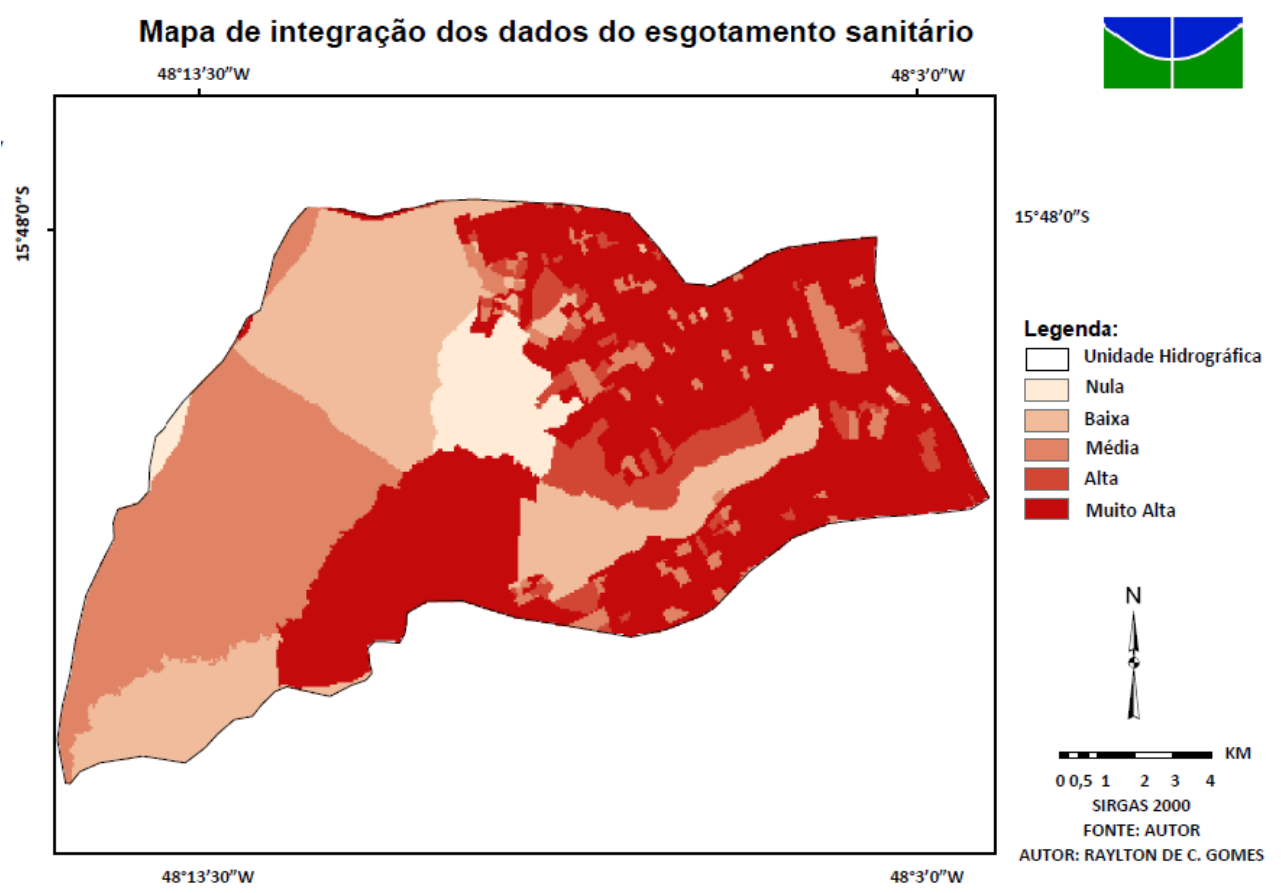

Figura 11 - Mapa de integração dos dados do esgotamento sanitário.

Para composição do tema Resíduos sólidos (Figura 12), foram utilizados dados de 8 (oito) produtos:

Outro destino do lixo, Lixo jogado em rio, lago ou mar, Lixo jogado em terreno baldio ou logradouro, Lixo enterrado na propriedade, Lixo queimado na propriedade, Lixo coletado em caçamba de serviço de limpeza, Lixo coletado por serviço de limpeza e Lixo coletado, obtidos da base do censo do IBGE (2010).

O mapa de integração dos dados da destinação dos resíduos sólidos demonstra a relação do uso do solo e às formas de gestão dos resíduos. Ou seja, as áreas localizadas sudoeste da bacia tendem a predominar o meio rural, cuja destinação do lixo tem maior participação em rios, lagos, em terrenos baldios ou logradouros, queimados e enterrados na propriedade, isso se deve à ausência de uma gestão eficaz, além da falta de informação sobre as formas corretas de destinação do lixo.

Já nas áreas nordeste da bacia predominam as zonas urbanas onde a maior parte dos resíduos é coletada por serviço de limpeza, por empresas do governo e cooperativas no caso de lixos recicláveis.

Nas áreas urbanas temos um processo mais eficaz de gestão de resíduos em comparação com as áreas rurais, no entanto, as áreas urbanas são áreas com maior geração de resíduos em comparação com as áreas rurais, assim, tendo maior influência no nível de conservação ambiental, dados que corroboram com os estruturados no modelo e no AHP e descritos pelo Censo.

Para composição do tema Água potável (Figura 13), foram utilizados 4 (quatro) produtos: Outra forma de abastecimento de água, Abastecimento de água de poço ou nascente na propriedade, Abastecimento de água da chuva armazenada em cisterna e Abastecimento de água de rede geral, obtidos da base do censo do IBGE (2010).

Com relação ao mapa de integração dos dados de abastecimento de água (Figura 13) foi possível analisar que na zona rural (predominante na área sudoeste da bacia) o abastecimento de água é realizado por meio da chuva e armazenado em cisterna e através de poço ou nascente na propriedade.

Já a parte nordeste da bacia, área mais urbanizada, verifica-se que a população faz o uso da rede geral de água, fornecida pela empresa de abastecimento responsável pela distribuição de água no Distrito Federal, que é a CAESB.De acordo com a figura 14, é possível verificar que as áreas a noroeste da bacia, cujo adensamento urbano é mais significativo com cerca de $30 \%$ da área, prevaleceu o nível de conservação muito alto e alto, esse fato pode ser explicado, devido, às áreas urbanizadas que possuem métodos eficazes para a coleta do esgoto, do lixo e do abastecimento de água, desempenhando menor influência em impactos 
ambientais causados na bacia em questão, apontando para a efetividade dos pesos definidos pelos especialistas e para estruturação do modelo AHP

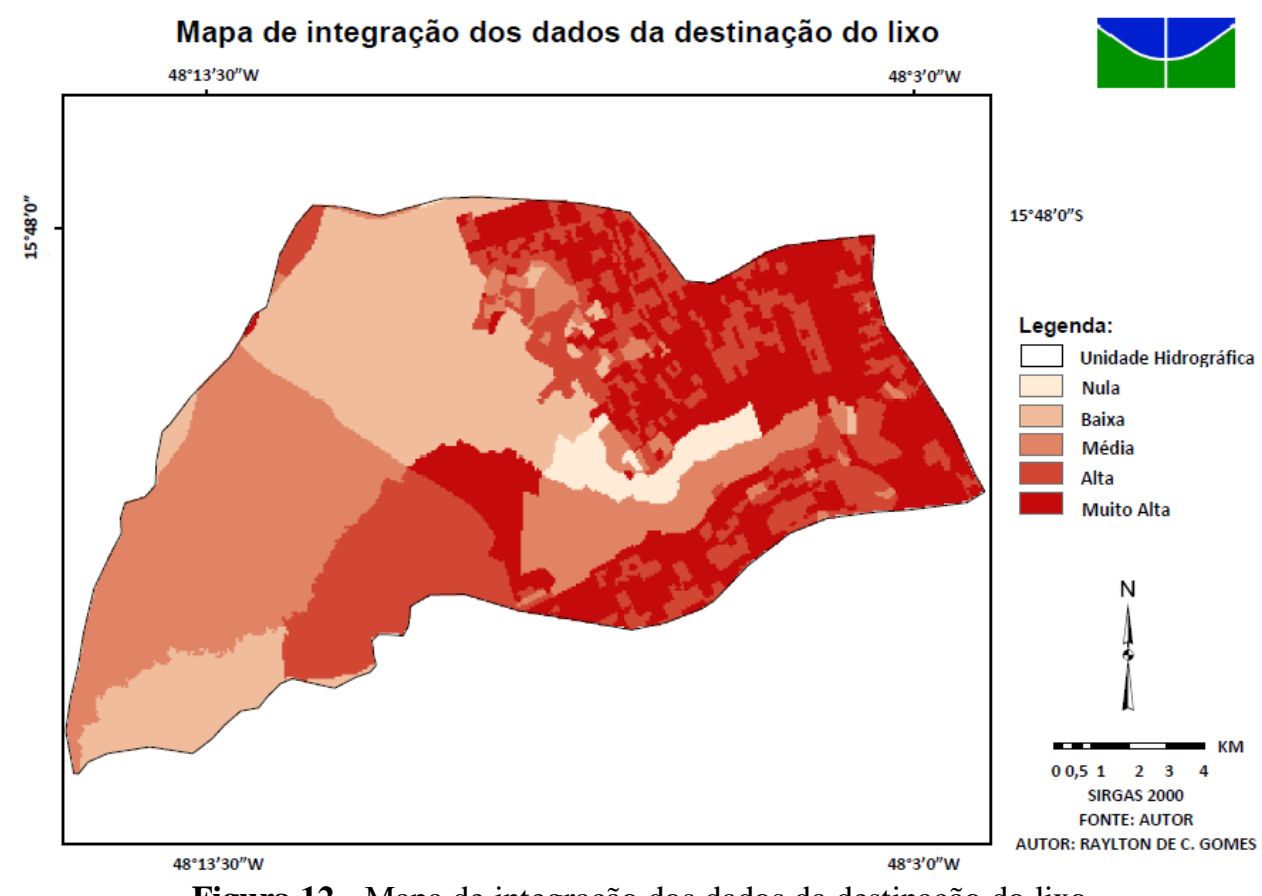

Figura 12 - Mapa de integração dos dados da destinação do lixo.

Verifica-se que a sudeste e na área central da bacia com $65 \%$ da área, prevaleceu o nível de conservação médio e baixo, com um número maior de domicílios em áreas rurais, esses são os principais responsáveis pelo impacto provocado pelos esgotos sanitários, sem tratamento, lançados no córrego Melchior ou em solo, lixo jogado em terreno baldio ou logradouros, enterrado ou queimado na propriedade, jogado em rio, estando em consonância com os dados obtidos pelo Censo.
Verifica-se que a sudeste e na area central da bacia com 65\% da área, prevaleceu o nível de conservação médio e baixo, com um número maior de domicílios em áreas rurais, esses são os principais responsáveis pelo impacto provocado pelos esgotos sanitários, sem tratamento, lançados no córrego Melchior ou em solo, lixo jogado em terreno baldio ou logradouros, enterrado ou queimado na propriedade, jogado em rio, estando em consonância com os dados obtidos pelo Censo.

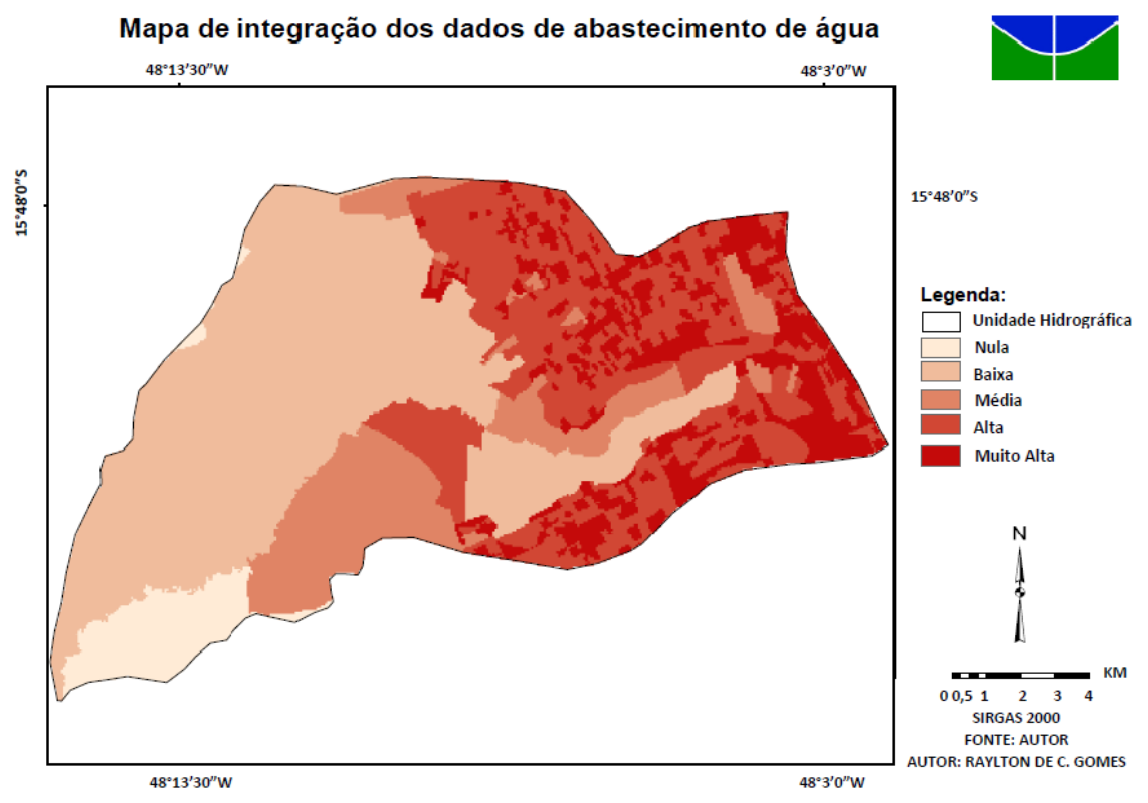

Figura 13 - Mapa de integração dos dados de abastecimento de água. 


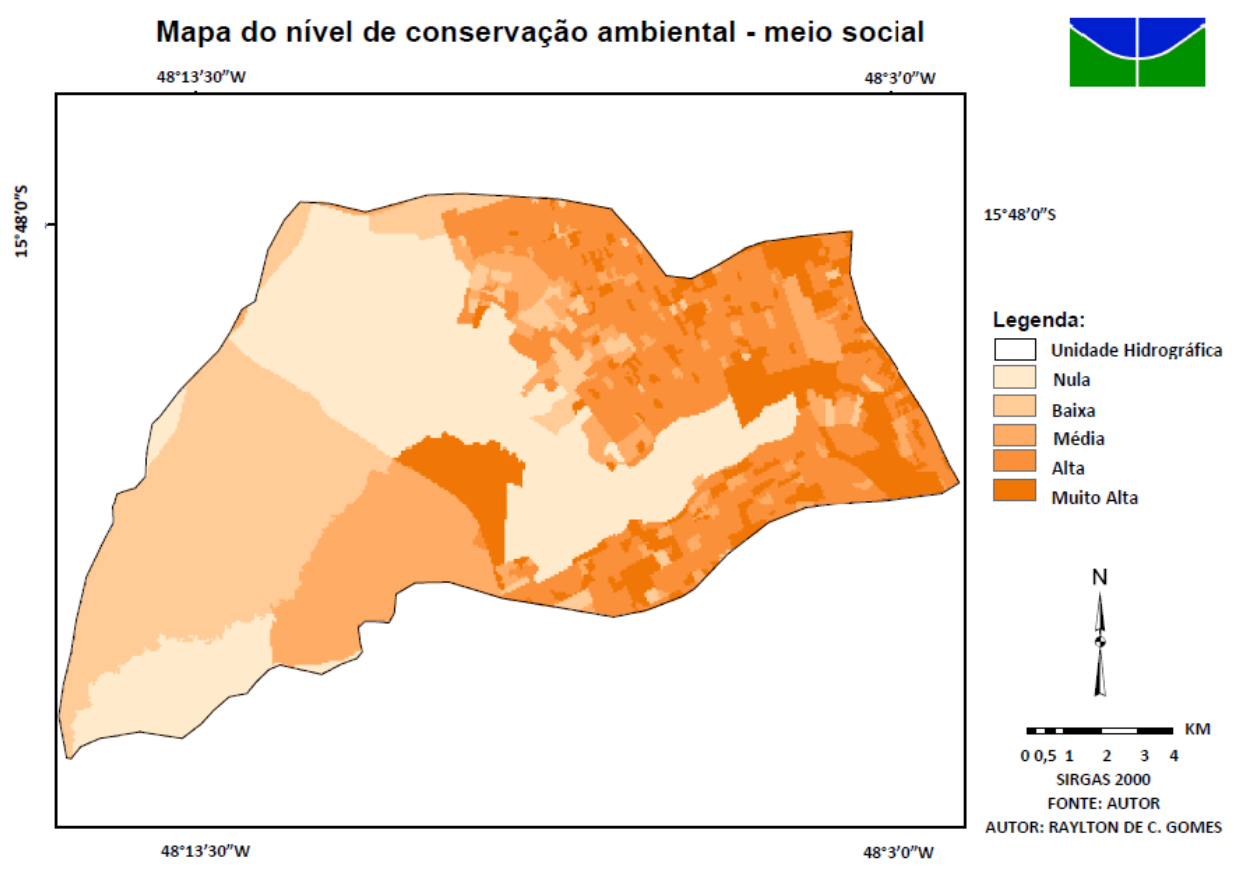

Figura 14 - Mapa de integração dos dados do meio social.

Por fim, a área central da bacia predomina o nível de conservação muito alto com $5 \%$ de representatividade, sendo uma área rural, com poucos domicílios, com menor geração de resíduos e esgotamento sanitário, classificada como área com o nível de conservação muito alto e alto nos mapas de integração do abastecimento de água, esgoto e destinação dos resíduos sólidos conforme figuras 11, 12 e 13 .

\section{Mapa do Nível de Conservação Ambiental da Bacia do Rio Melchior}

Da análise do mapa do Nível de Conservação Ambiental da Bacia do Melchior (Figura 15), destacam-se com maior relevância os seguintes elementos:

- Mapa de integração do meio físico com peso 0,750 ;

- Mapa de integração do meio social com peso de 0,250 .

Algumas considerações devem ser apontadas com relação ao meio físico e social e a sua influência na bacia e que são analisadas a partir de sua integração (Figura 15). São elas:

- 16 \% da bacia foi classificada com o nível de conservação ambiental nula;

- 16 \% da bacia foi classificada com o nível de conservação ambiental baixa;

- 26 \% da bacia foi classificada com o nível de conservação ambiental média;

- 30 \% da bacia foi classificada com o nível de conservação ambiental alta;

- 12 \% da bacia foi classificada com o nível de conservação ambiental muito alta.

Destaca-se a área nordeste da bacia como a área que tem os níveis de conservação ambiental baixo e nulo, apresenta uma grande fragilidade ambiental e nela estão as maiores extensões de ocupação urbana com e sem infraestrutura, bem como os maiores índices de consumo de água, geração dos resíduos sólidos e lançamento de esgoto.

Observa-se também que as áreas urbanizadas localizadas na área noroeste da bacia foram classificadas com o nível de conservação ambiental nulo e baixo, essa diferença pode ser explicada, pelo fato das áreas urbanas terem sido classificadas no modelo como áreas com infraestrutura e sem infraestrutura, essa diferença refletiu no nível de conservação ambiental da bacia. Observa-se, que entre as cidades satélites de Ceilândia, Samambaia e Taguatinga, classificadas com o nível de conservação ambiental muito alto, alto e médio (Figura 15), encontramos uma grande quantidade de áreas verdes (parques), que são utilizados na maioria das vezes para o lazer da população.

A mata de galeria que recebeu o maior peso no processo de julgamento do uso do solo, sendo o uso do solo o elemento com maior peso na segunda etapa de julgamento, integrando o meio físico que na terceira etapa de julgamento teve o maior peso em comparação com o meio social, sendo, portanto, a mata de galeria um dos elementos que maior influência na qualidade ambiental da bacia. 


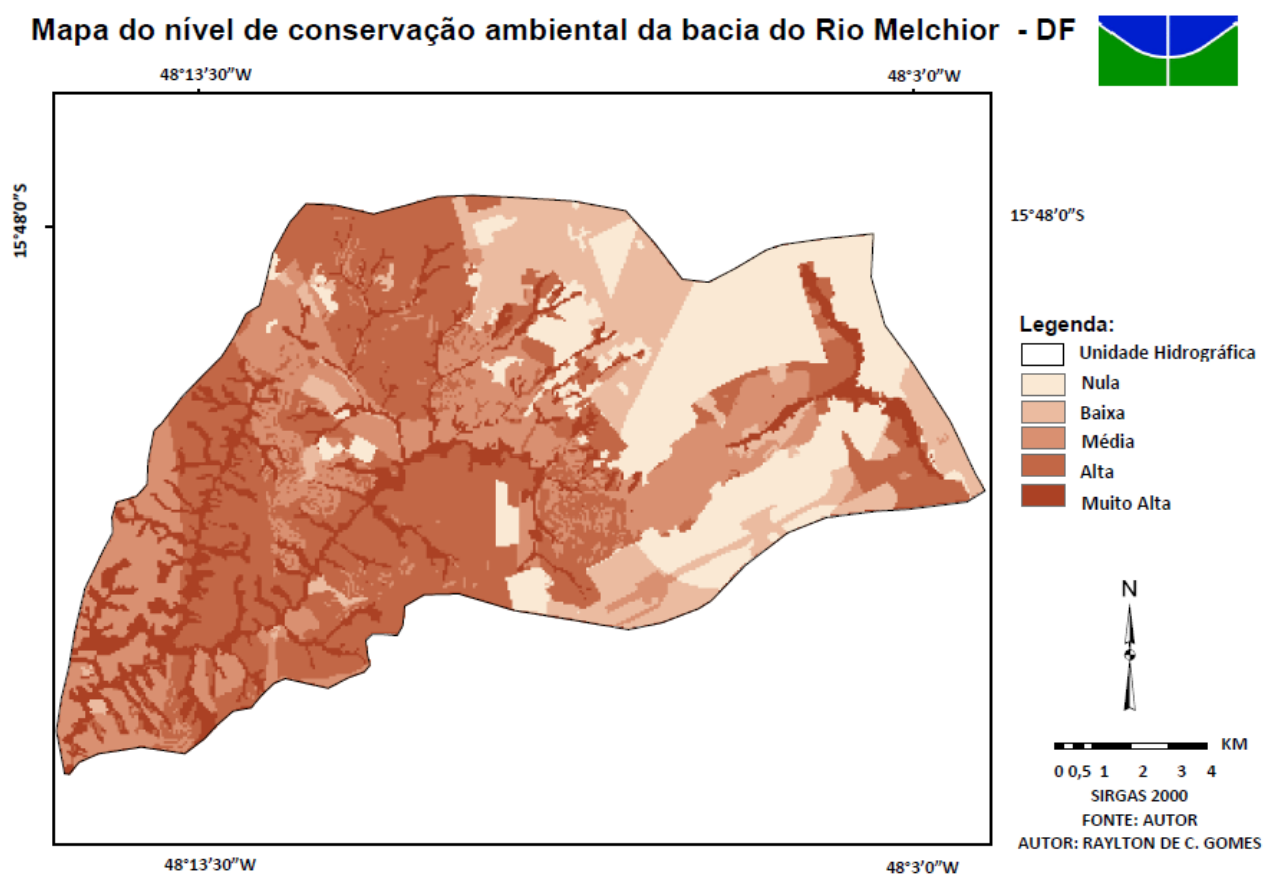

Figura 15 - Mapa do Nível de Conservação Ambiental da Bacia do Melchior - DF.

A região sudoeste da bacia é onde se concentra os níveis de conservação ambiental alto é médio, são áreas menos urbanizadas com maior cobertura vegetal, onde predomina as atividades rurais, com uma menor impermeabilização do solo e baixa geração de resíduos sólidos e esgoto.

Vale ressaltar, que na área sudoeste da bacia encontra-se pequenas áreas com o nível de conservação ambiental baixo e nulo, essas áreas são reflexos de pequenas ocupações, condomínios ou invasões instaladas nesses locais, que devido a sua geração de resíduos sólidos, esgoto, impermeabilização do solo, falta de direcionamento de água, entre outros, contribuem para a área ter um menor nível de conservação ambiental.

\section{CONCLUSÕES}

$\mathrm{O}$ resultado da presente pesquisa demonstrou a viabilidade da integração de ferramentas de geotecnologias e de aplicativos de análise hierárquica para modelagem de integração, visando analisar a qualidade ambiental de bacias hidrográficas, otimizando o tempo e garantindo a qualidade das informações, gerando mecanismos de tomada de decisões para os gestores ambientais.

Constatou-se que as áreas urbanas são as que apresentaram maiores fragilidades ambientais, bem como as maiores áreas impermeabilizadas, a maior geração de esgoto, de lixo e de consumo de água e as menores áreas verdes. $\mathrm{O}$ uso do SIG e do AHP mostrou-se útil para aplicações de análise de qualidade ambiental.

No entanto, a integração dos métodos e modelos sinalizaram indicativos que devem ser observados em campo para uma melhor aplicação de medidas corretivas e ajuste a um planejamento ambiental de longo prazo. O modelo AHP mostrou-se bastante versátil, permitindo a aplicação de critérios e alternativas na modelagem de processos de análise de qualidade ambiental em bacias hidrográficas. No entanto, nos pesos definidos pelos especialistas na estruturação do modelo AHP, observou-se uma limitação na caracterização da qualidade ambiental da área urbana, o modelo não conseguiu demonstrar da mesma forma a qualidade ambiental da área urbana com infraestrutura, pois nela existe todo um sistema de fornecimento de água potável, coleta de lixo e sistema de coleta de esgoto. Com base nessa limitação recomenda-se uma maior estratificação da área urbana em função dos padrões existentes.

Os dados obtidos do IBGE mostraram-se úteis e de grande importância para a realização da pesquisa, mas vale ressaltar que alguns dados não expressam bem a verdadeira realidadade da bacia, devendo ser analisados e até mesmos ajustados, visando não comprometer o objetivo da pesquisa. 


\section{AGRADECIMENTOS}

Agradecemos ao CNPQ a concessão da bolsa de mestrado que permitiu a consecução da presente pesquisa.

\section{REFERÊNCIAS}

ABRELPE. Panorama dos resíduos sólidos no Brasil 2013. Associação Brasileira de empresas de Limpeza, 114p., 2013.

BERNARDI, E.C.S.; PANZIERA, A.G.; BURIOL, G.A.; SWAROWSKY, A. Bacia Hidrográfica como Unidade de Gestão Ambiental. Ciência Naturais e Tecnológicas, v. 13, p. 159-168, 2013.

CALLISTO, M.; FERREIRA, W.R.; MORENO, P.; GOULART, M.; PETRUCIO, M. Aplicação de um protocolo de avaliação rápida da diversidade de habitats em atividades de ensino e pesquisa (MG-RJ). Acta Limnologica Brasiliensia, v. 14, p. 91-98, 2002.

CODEPLAN. Mapas Topográficos Planialtimétricos Digitais do Distrito Federal na escala de 1:10.000. GDF, 1992. Brasília.

CONAMA. Resolução CONAMA $\mathbf{N}^{0} \mathbf{0 0 1}$, de 23 de janeiro de 1986. Disp. em: <http://www.mma.gov.br/port/ conama/res/res86/res0186.html>. Acesso em: 5/5/2014.

COSTA, H.G. Introdução ao Método de Análise Hierárquica. In: SBPO, XXXVI, 2004. São João Del Rei. Disp. em: <http://www.din.uem.br/sbpo/sbpo2004/pdf/arq0279.pdf>.

EMBRAPA. Mapa Pedológico Digital - SIG Atualizado do Distrito Federal Escala 1:100.000 e uma Síntese do Texto Explicativo. Planaltina, DF, 2004.

ESRI. Programa de computador. Arc Gis (versão 10.2), 2013. Estados Unidos.

EXPERT CHOICE RESOURCE ALIGNER. Programa de computador. Expert Choice (versão 3.01), 2004. Estados Unidos.

FRANCO, J.L.D.A. O que podemos fazer para evitar a destruição de nosso mundo?. Sociedade e Estado, v. 24, n. 1, p. 293-299, 2009.

GONÇALVES, T.D. Geoprocessamento como ferramenta de apoio à gestão dos recursos hídricos subterrâneos do Distrito Federal, 2007. Brasília: Universidade de Brasília.

LOPES, P.M. \& PEJON, O. Obtenção da Carta de Susceptibilidade À Erosão com Auxílio do Sig-Idrisi: Subsídio Para O Zoneamento Geoambiental da Bacia do Rio Passa Cinco e Rio da Cabeça - Sp. In: SIMPÓSIO NACIONAL DE CONTROLE DE EROSÃO, VII, 2001. p. 1-10, Disp.em: <http://www.labogef.iesa.ufg.br/links/ simposio_erosao/articles/T020.pdf $>$.

MARINS, C.S.; SOUZA, D.O.; BARROS, M.S. O uso do método de análise hierárquica (AHP) na tomada de decisões gerenciais - um estudo de caso. In: SBPO, XLI 2009 Pesquisa Operacional da Gestão do Conhecimento, p. 1778-1788, 2009.

MENDOZA, M.E.; LÓPEZ, E.; GENELETTI, D.; PÉREZSALICRUP, D.R. Analysing land cover and land use change processes at watershed level: A multitemporal study in the Lake Cuitzeo Watershed, Mexico ( 1975 e 2003 ). Applied Geography, v. 31, n. 1, p. 237-250, 2011. Elsevier Ltd.

NOVAIS, V.M.S. Desafios para uma efetiva gestão ambiental no Brasil, p. 1-14, 2011.

PEIXOTO, M.C.D. Expansão urbana e proteção ambiental: um estudo a partir do caso de Nova Lima /MG. In: ENCONTRO NACIONAL DE PÓS-GRADUAÇÃO E PESQUISA EM PLANEJAMENTO AMBIENTAL URBANO E REGIONAL-ANPUR, XI, 2005, Salvador. Anais...Salvador: ANPUR, 2005

PIROLI, E.L. \& CAMPOS, S. Análise do uso da terra por classes de declividade em microbacia hidrográfica usando geoprocessamento. Pesquisa Aplicada \& Agrotecnologia, v. 2, p. 7-20, 2009.

REIS, H.L.A.; NOGUEIRA, L.; NEVES BRITO, F.; MARCELO, N.S.; FRANCO, M. N. S.; ARAUJO, M. M.L.; BARBOSA, W.W.P.; TEZA, C.T.V.; ALBUQUERQUE, S.M.; RESENDE, M.G. Índice de Qualidade da Água do córrego Vicente Pires-DF, sua relação com o uso e ocupação do solo e influência sobre o córrego Riacho Fundo-DF. In: SIMPÓSIO BRASILEIRO DE SENSORIAMENTO REMOTO, XVI, 2013, Foz do Iguaçu. Anais... Foz do Iguaçu: INPE, p. 928-935, 2013.

RIBEIRO, J.C. \& SALOMÃO, F.X.T. A Morfopedologia Aplicada ao Diagnóstico e Prevenção dos Processos Erosivos Lineares da Bacia Hidrográfica do Alto Rio da Casca. In: SIMPÓSIO NACIONAL DE CONTROLE DE EROSÃO, VII, Goiania, 2001. Anais...:Goiania: Associação Brasileira de Geologia e de Engenharia Ambiental, p. 1-9,

RIBEIRO, M.O. Estudo da poluição e autodepuração nos rios Melchior e Descoberto, na bacia do Descoberto - DF / GO, com auxílio de modelos matemáticos de simulação de qualidade de água, para estudos de seu comportamento atual e futuro, 2001. Universidade de Brasília - UnB.

SÁNCHEZ, L.E. Avaliação de impacto ambiental. $1^{\circ}$ ed. São Paulo: Oficina de textos, 2008.

SEDHAB. PDOT - Processo de Atualização. Disp. em: $<$ http://www.sedhab.df.gov.br/desenvolvimentourbano/planejamento-urbano/pdot/processo-de-atualizacaopdot.html>. Acesso em: 5/5/2014.

SEDHAB. Plano Diretor de Ordenamento Territorial do Distrito Federal (2015). Disp. em: <http://www.sedhab.df.gov.br/...urbano/...pdot/processo-deatualização-pdot.html>. Acesso em: 15/1/2015.

SHARAFI, S.M.; MOILANEN, A.; WHITE, M.; BURGMAN, M. Integrating environmental gap analysis with spatial conservation prioritization: a case study from Victoria, Australia. Journal of environmental management, v. 112, p. 240-51, 2012.

SILVA, A.C.; TORRADO, P.V.; PÉREZ, M.G.; NETO, L.M.; VASQUEZ, F.M. Relações entre matéria orgânica do solo e declividade de vertentes em toposseqüência de latossolos do sul de Minas Gerais. Revista Brasileira de Ciencia do Solo, v. 31, n. 5, p. 1059-1068, 2007.

SILVA, J.X. \& ZAIDAN, R.T. Geoprocessamento \& Meio Ambiente (orgs). Rio de Janeiro: Bertrand Brasil, 2011.

XAVIER, L.S.S. Implicações socioambientais do turismo e o licenciamento na Bacia do Rio Formoso, Bonito, MS. 2011, São Paulo. Tese (Doutorado), Universidade de São Paulo, Interunidades em Ecologia Aplicada.

ZHAO, M.; ZHANG, Y.; MA, W.; FU, Q.;XINYANG, X.; LI, C.; ZHOU, B.; YU, Q.; CHEN, L. Characteristics and ship traffic source identification of air pollutants in China's largest port. Atmospheric Environment, v. 64, p. 277-286, 2013.

ZHOU, J.L.; BAI, Z.H.; SUN, Z.Y. A hybrid approach for safety assessment in high-risk hydropower-constructionproject work systems. Elsevier Ltd, Safety Science, v. 64, p. 163-172, 2014.

Submetido em 8 de julho de 2015 Aceito em 13 de outubro de 2017 